\title{
The publication of population genetic data in the International Journal of Legal Medicine: guidelines
}

\author{
Micaela Poetsch • Thomas Bajanowski • Heidi Pfeiffer
}

Published online: 6 May 2012

(C) Springer-Verlag 2012

Population data are an important part of forensic genetics, since allele frequencies are needed for any statistical evaluation. But the presentation of these data in a full manuscript is rather boring/cumbersome for the reader, because a major part of the information is similar for each manuscript. To avoid these problems, there is a new possibility to publish population genetic data in the International Journal of Legal Medicine called "Population data". Here, we describe this new article type of the journal to give potential authors an idea how it should be structured.

All manuscripts submitted as "Population data" should contain an abstract of no more than 80 words. The number of authors is restricted to six, the number of references is restricted to ten. Description of material and methods, results and conclusions has to be done in a continuous text which should not be longer than half a printed page in the journal. All data (e.g. allele frequencies and forensic effi-

\footnotetext{
M. Poetsch $(\bowtie) \cdot$ T. Bajanowski

Institut für Rechtsmedizin, Universitätsklinikum Essen,

Hufelandstr. 55,

45122 Essen, Germany

e-mail: micaela.poetsch@uk-essen.de

T. Bajanowski

e-mail: Thomas.Bajanowski@uk-essen.de

\section{H. Pfeiffer}

Institut für Rechtsmedizin, Westfälische Wilhelms-Universität, Röntgenstrasse 23,

48129 Münster, Germany

e-mail: pfeiffh@uni-muenster.de
}

ciency parameters) will be published as electronic supplemental material (ESM).

The continuous text must include a characterization of the population investigated, the description of the ethic considerations, and a specification regarding validation efforts (e.g. the analysis of well-known cell lines) and quality management. In addition, comparisons with other populations should be done, including a statement why those populations have been chosen for comparison. Here, the data will also be published as ESM. If appropriate, peculiarities of the investigated population(s) may be added. Y chromosomal data or mtDNA sequences must be sent to the YHRD database (http://www.yhrd.org/Contribute) or EMPOP database (http://www.empop.org/modules/contribute) as outlined by Parson and Roewer [1].

There is still the possibility to submit population analyses as "Short communication" or even as "Original article", but in this case, at least three different marker categories must be investigated (e.g. autosomal STRs, X chromosomal STRs and Y chromosomal STRs) in a high-quality analysis. In addition, the manuscript must describe a population which was never or only rarely investigated before or the results must have an important impact on evolution theories. In any case, the editors reserve the right to ask the authors to resubmit their manuscript as "Population data".

In the following, an example is given how to prepare a manuscript as "Population data". Vineta, a legendary town at the Baltic Sea, possibly located in what is now northern Germany, is used as an example for this kind of manuscript, imagining that it has not perished in a flood and was not destroyed by invaders. 
A fictional example of a population data paper: allele frequencies for eleven X-chromosomal STRs in a population sample from Vinetaa legendary town at the Baltic Sea

Nils Holgerson, Magnus I. of Norway, Canute V. of Denmark, Swen III of Denmark, Henry the Lion of Saxonia

\section{Abstract}

Since the $10^{\text {th }}$ or $11^{\text {th }}$ century $\mathrm{AD}$, Vineta has been a major trade city at the Baltic Sea. It is generally assumed that the population consists of Wends and Slavs. Here, we analyzed eleven X chromosomal STRs in 200 women and 300 men who could prove their ancestry in Vineta for at least twenty-five generations and compared the results with German, Polish, Finnish and Swedish populations.

For almost 200 years Vineta was the most important harbour at the South of the Baltic Sea, and even after the Wendish Crusade in the $12^{\text {th }}$ century $\mathrm{AD}$, a part of the Christianisation efforts in this geographical region, it remained a major trade city. Buccal swabs from 200 women and 300 men have been analyzed after informed consent and thorough discussion with the responsible priests in eleven $\mathrm{X}$ chromosomal STRs combined to two multiplexes. Samples were obtained and analyzed after advice of the Medical Ethics Committee of the University of Vineta in accordance with the declaration of Helsinki. The anonymity of the individuals investigated was preserved corresponding to the rules of data protection of the Human Medical Faculty Vineta. DNA extraction, PCR, analysis on an ABI310 genetic analyzer and statistical evaluation have been done as described before [2]. The allele frequencies and the results of the forensic efficiency parameter calculations are given in Table S1 and Table S2. Combined forensic efficiency parameters were calculated for all STRs with the exception of DXS7424, for which linkage disequilibrium to DXS101 has previously been detected [3], as follows: combined power of discrimination for males 0.99999999 , combined power of discrimination for females greater than 0.999999999 and combined mean exclusion chance for trios 0.999991 . The frequency of DXS101-DXS7424 haplotypes is shown in Table S3. Linkage disequilibrium between DXS101 and DXS7424 has not been tested for our samples because the number of investigated individuals was too small. Two rare alleles were found in the samples from Vineta, the allele 61 in DXS8377 and the allele 7.3 in DXS9898. Both have been verified by sequencing as described before [2]. Genetic distances were estimated for each STR marker with the exception of DXS7424 - due to the linkage disequilibrium to DXS101 - to different European populations [4-8] and
non-European populations [9, 10] as available (see Table S4 for results). In summary, there were only few differences between the peoples from Vineta and other Northern European populations, but major differences to the populations from Brazil and the Ivory Coast, as expected.

\section{References}

1. Parson W, Roewer L (2010) Publication of population data of linearly inherited DNA markers in the International Journal of Legal Medicine. Int J Legal Med 124:505-509

2. Poetsch M, Knop A, El-Mostaqim D, Rakotomavo N, von WurmbSchwark N (2011) Allele frequencies of 11 X chromosomal STRs of two African populations. Int J Legal Med 125:307-314

3. Edelmann J, Hering S, Kuhlisch E, Szibor R (2000) Validation of the STR DXS7424 and the linkage situation on the X-chromosome. Forensic Sci Int 125:217-222

4. Poetsch M, Sabule A, Petersmann H, Volksone V, Lignitz E (2006) Population data of ten X chromosomal loci in Latvia. Forensic Sci Int 157:206-209

5. Edelmann J, Deichsel D, Hering S, Plate I, Szibor R (2002) Sequence variation and allele nomenclature for the X-linked STRs DXS9895, DXS8378, DXS7132, DXS6800, DXS7133, GATA172D05, DXS7423 and DXS8377. Forensic Sci Int 129:99-103

6. Vauhkonen H, Vauhkonen M, Sipponen P, Sajantila A (2004) Correlation between the allelic distribution of STRs in a Finnish population and phenotypically different gastrointestinal tumours: a study using four X-chromosomal markers (DXS7423, DXS8377, ARA, DXS101). Ann Hum Genet 68:555-562

7. Luczak S, Rogalla U, Malyarchuk BA, Grzybowski T (2011) Diversity of 15 human X chromosome microsatellite loci in Polish population. Forensic Sci Int Genet 5:e71-e77

8. Tillmar AO, Mostad P, Egeland T, Lindblom B, Holmlund G, Montelius K (2008) Analysis of linkage and linkage disequilibrium for eight X-STR markers. Forensic Sci Int Genet 3:37-41

9. Penna LS, Silva FG, Salim PH, Ewald G, Jobim M, Magalhaes JA, Jobim LF (2012) Development of two multiplex PCR systems for the analysis of $14 \mathrm{X}$-chromosomal STR loci in a southern Brazilian population sample. Int J Legal Med 126:327-330

10. Pasino S, Caratti S, Del Pero M, Santovito A, Torre C, Robino C (2011) Allele and haplotype diversity of X-chromosomal STRs in Ivory Coast. Int J Legal Med 125:749-752 